\title{
Bakthin e a filosofia do ato na pesquisa e no ensino: uma experiência acadêmica na Universidade Federal de Pernambuco (Brasil)
}

\author{
Maria Cristina Hennes Sampaio ${ }^{1}$
}

\begin{abstract}
The subject matter of this paper was inspired in our experience in research and teaching on the Postgraduate Linguistics and Arts Program at the Federal University of Pernambuco, in Brazil's Northeastern region between 2007 and 2015, which led to the publication of papers, academic magazine articles, chapters in books, research projects, dissertations and theses. To that end the intention is to analyze to what extent the study of Bajtin's (1997a) work, "Towards a philosophy of the ethical act" , written between 1920 and 24, seen from the different philosophical traditions (phenomenology, ontology, metaphysics and hermeneutics) in the Philosophy of Language subject of the Postgraduate Arts Program, offered a fruitful dialog between research and teaching, benefiting the manner in which young people at the research initiation level as well as Masters and Doctorate candidates approach subjectivity in their own academic studies, and the consequences of inaugurating a new place for ethical and philosophical observation for language research and teaching.
\end{abstract}

Keywords: Bakhtin; philosophy; experience; research; teaching.

Resumo: O tema deste ensaio foi inspirado na nossa experiência em pesquisa e ensino no Programa de Pós-Graduação em Linguística e Letras, da Universidade Federal de Pernambuco, no Nordeste do Brasil, no período entre 2007-15, a qual resultou na publicação de ensaios, artigos em revistas acadêmicas, capítulos de livros, projetos de pesquisa, dissertações e teses. Neste sentido, pretende-se analisar em que medida o estudo da obra de Bakhtin, Para uma filosofia do ato ético, escrita entre 1920-24, visto sob diversas tradições filosóficas (fenomenologia, ontologia, metafísica e hermenêutica), na disciplina Filosofia da Linguagem, do Programa de Pós-Graduação em Letras, propiciou um profícuo diálogo entre pesquisa e ensino, favorecendo a forma de jovens alunos de iniciação científica, mestrandos e doutorandos abordarem a subjetividade em seus próprios estudos acadêmicos e as consequências de inaugurar um novo lugar de observação ético-filosófica para a pesquisa e o ensino de línguas.

Palavras-chave: Bakhtin; filosofia; experiência; pesquisa; ensino.

1 Docente dos Cursos de Graduação e Pós-Graduação em Letras da Universidade Federal de Pernambuco. Pós-Doutorado em Estudos da Linguagem e Linguística Aplicada. Atualmente desenvolve Pesquisas em Filosofia da Linguagem. 
O objetivo desse artigo é examinar em que medida o estudo da obra Por uma filosofia do ato ético, de Bajtin (1997a), no âmbito de diversas tradições filosóficas, contribuiu para reorientar as formas de abordagem da subjetividade nos nossos projetos e estudos e de nossos alunos de Pós-graduação da Universidade Federal de Pernambuco (UFPE), no nordeste brasileiro, e suas consequências para inaugurar um outro lugar de observação ético-filosófica de pesquisa da linguagem. Partimos da premissa que uma coisa são os conhecimentos científicos e filosóficos que detemos sobre a linguagem e outra são as experiências pensantes que fazemos com ela. Isso pressupõe reconhecer que existem diferenças fundamentais entre as tarefas da razão $(\log o s)$ e do pensamento. Para se fazer uma experiência pensante, com a linguagem, não se pode permanecer numa pré-compreensão de um mundo já dado, conhecido, explicado, de um sentido estabilizado. Assim, os temas privilegiados nos estudos em torno das ideias filosóficas bakhtinianas, parecem sinalizar que o projeto filosófico de Bajtin (1997a), em relação à experiência com a linguagem, indicam um caminho diferente daquele proposto pelas ciências, particularmente a linguística, a metafísica e a psicologia, que só pode concretizar-se na experiência vivida.

\section{A ética filosófica enquanto disciplina}

A ética enquanto disciplina filosófica pressupõe um vasto campo de conhecimentos que desde a Grécia antiga até a contemporaneidade tem levantado questões e procurado respostas relativas à ação e à moral dos seres humanos. Na filosofia contemporânea a discussão sobre a ética retoma uma questão de base da metafísica clássica: o que é o homem? Trata-se de uma ética forjada na temporalidade e pelo fluxo da existência, já que o ser, como pretendia Bajtin (1997a: 78), encontra seu sentido na temporalidade: "apenas o valor do homem mortal fornece padrões para medir as ordens espaciais e temporais, considerando que o espaço constitui o horizonte possível desse homem", e "o tempo lhe atribui peso e densidade valorativa". Ou seja, é a real participação do homem, em sua unicidade, que garante a consolidação de todo o tempo e espaço matematicamente possíveis.

Nesse sentido, cabe ressaltar que no contexto soviético da cultura russa do século XX, Mikhail Bakhtin, (1895-1975), foi uma das poucas personalidades russas a sobressair-se no âmbito da filosofia e ter suas ideias reconhecidas e amplamente divulgadas no ocidente. É na obra Por uma Filosofia do Ato Ético. De los borradores e otros escritos, escrita em seus anos de juventude, que Bajtin (1997a) vai defender uma ética da responsabilidade na abordagem do acontecimento do ser, antecipando, assim, questões epistemológicas e éticas que diziam respeito ao conhecimento produzido pelo pensamento teórico discursivo (ciências naturais e filosofia) o qual, de seu ponto de vista, seria incapaz de apreender o acontecimento em sua unicidade, argumentando que toda a razão teórica não seria senão um momento da razão prática, ou seja, da razão que vem da orientação moral de um sujeito no acontecimento singular no ser.

Assim sendo, retomando o conceito de ato ético responsável, desenvolvido por Bajtin (1997a), partimos do pressuposto que este saber ético deva ser buscado em um horizonte mais originário daquele legado pela tradição ocidental, ou seja, de um ponto de vista ontológico-historial.

Se a compreensão do ato responsável deve ser buscada no acontecimento do ser na vida, é necessário refletir sobre a forma de seu aparecimento na existência. Para tanto Ba- 
jtin (1997a) vai lançar a ideia de uma arquitetônica concreta do mundo do ato realizado, orientada pelo valor, contrapondo-a à análise da arquitetônica do mundo da visão estética, com a qual compartilha algumas características. Para ele (BAJTIN, 1997a: 60), se o acontecimento do ser é composto de momentos constituintes comuns em suas várias arquitetônicas concretas, uma "filosofia moral deveria ocupar-se em descrever esta arquitetônica do mundo real do ato ético, não em forma de esquema abstrato, mas como um plano concreto do mundo do ato unitário e singular, dos momentos principais de sua estruturação e de sua disposição recíproca" cujos momentos são: "o eu-para mim, o outro para mim e o eu para-o-outro". Para o filósofo (BAJTIN, 1997a: 61) "todos os valores da vida real e da cultura encontram-se dispostos, espaço-temporalmente, em torno desses momentos emocionais e volitivos do mundo do ato ético: valores científicos, estéticos, políticos, éticos, sociais, religiosos, etc." Para ele (BAJTIN, 1997a: 62), "o fundamento do ato encontra-se em comunhão com a totalidade", o que equivale dizer que o responsável não se dissolve no especializado, pois, se assim fosse, deixaria de ser um ato ético para ser uma ação técnica. Assim sendo - argumenta, "um tal ato ético não deve separar teoria e pensamento, mas incluí-los dentro de si como momentos necessários e plenamente responsáveis."

$\mathrm{Na}$ análise do ato responsável e do acontecimento do ser, Bajtin (1997a) sugere a necessidade de demonstrar a forma como se dá a inserção/apropriação do ato em um mundo singular e único vivido de forma concreta visto, ouvido, apalpado e pensado, impregnado por tonalidade emocional/afetiva e volitiva. Nesse sentido Bajtin (1997a: 63) insiste na ideia de que "a singulariade do mundo não tem origem em nenhum conteúdo semântico, já que é de ordem emocional e volitiva, e o que garante a nossa participação singular no mundo é o nosso não-álibi no ser." Isso significa que essa nossa participação no ser não é casual nem fortuita, mas um dever, um comprometimento, uma responsabilidade com a singularidade da existência no acontecimento do ser a qual transforma cada manifestação nossa, em forma de pensamento, sentimento, desejo, estado de ânimo, em um ato ativo e responsável exclusivamente nosso. Além disso, esta nossa participação no acontecimento do ser ,"cria uma gravidade real do tempo e um valor palpável e manifesto do espaço no mundo, convertendo-o num todo único e singular, real e responsavelmente vivenciado" (BAJTIN, 1997a: 64). Quando isso não acontece, isto é, se nos abstraimos "desse centro de irradiação" de nossa "participação única no ser, então esta arquitetônica concreta de um mundo vivenciado será substituída por uma unidade sistemática de momentos abstratos e gerais, sem valor espaço-temporal e axiológico" e "seu sentido ficará centrado em si mesmo" (BAJTIN, 1997a: 64-5). Nesse ponto Bajtin (1997a) questiona a natureza do sentido em sua durabilidade ou seja, se a sua eternidade seria axiologicamente possível. Argumenta que se isso fosse possível, ou seja, se "a eternidade do sentido fosse axiologicamente válida, então seu raciocínio e realização efetivas, mediante o pensamento ativo, seria desnecessário", insistindo que "somente em relação com a realidade, o sentido eterno" - no nosso entendimento, aquilo que já está dado na realidade -, "converte-se em força motriz do pensamento" efetivamente realizado. Podemos concluir, com isso, que para ser-no-mundo é preciso levar em consideração a relação daquilo que já está dado e conhecido como verdade eterna, com o centro axiológico único possibilitado pela responsabilidade do ato de pensamento efetivamente realizado. No próximo tópico iremos analisar em que medida pensamento e linguagem caminham juntos. 


\section{Uma experiência pensante com a linguagem}

O que significa fazer uma experiência pensante com a linguagem? Para responder a esta questão, Bajtin (1997a) sugere que a palavra viva, a palavra completa, não designa meramente um objeto como uma entidade pronta, mas expressa a nossa atitude valorativa sobre ela, deixando, em aberto, aquilo que ainda está para ser determinado nela. Sendo assim, fazer uma experiência com a linguagem parece ser bem distinto de adquirir conhecimentos linguísticos sobre a linguagem pela ciência linguística, pela filologia ou pela psicologia, através da produção de uma metalinguagem que equivaleria à metafísica, numa tentativa de tecnicização das línguas para torná-las instrumentos de uma comunicação interplanetária.

Em textos posteriores a 1920, ao falar sobre a bipolaridade do texto, Bakhtin (1997b) vai fazer a distinção entre dois níveis da palavra: tema e significação, indicando que o primeiro remete àquele elemento único, não reiterável da enunciação, ao seu sentido completo; já o segundo estaria no nível da língua, na qual os elementos da enunciação são reiteráveis e idênticos a cada vez que são repetidos, constituindo apenas um nível inferior da interpretação. A relação entre o "ser" e a "linguagem", o "mundo" e a "mente", o "dado" e o "criado", também é tema recorrente na obra filosófica de Bakhtin, conforme observado por Michael Holquist ${ }^{2}$, abrindo espaço para a noção do dialogismo distintivo o qual viria a ser desenvolvido em suas obras posteriores.

Por conseguinte, a ideia de que a expressão do ato responsável requer a plenitude da palavra conduz o filósofo a questionar sua natureza mais originária na tentativa de ir além da relação coisa e palavra, ser e dizer. É a linguagem que detém a guarda tanto do ser das coisas como também do modo de acontecer do evento, na medida em que ela circunscreve o campo da nossa possível experiência no mundo. Diferentemente do que acontece na metafísica, na qual a linguagem presta-se para comunicar ou manipular o sujeito, é preciso reconhecer que é a linguagem que proporciona a abertura do mundo.

Nos próximos tópicos faremos um relato sobre os desdobramentos dos aportes da filosofia da linguagem de Bakhtin na nossa experiência com a pesquisa e o ensino, em curso de Pós-graduação em Letras de uma universidade pública brasileira.

\section{Pesquisa e docência: experiências junto ao Programa de Pós-Graduação em Letras}

Nossa experiência em pesquisa e docência, junto ao Programa de Pós-Graduação em Letras da Universidade Federal de Pernambuco (UFPE), como líder do Grupo de Pesquisa UFPE-CNPq Linguagem, Sociedade, Saúde e Trabalho ${ }^{3}$ e membro do Grupo de Pesquisa PUC-CNPq Linguagem, Identidade e Memória ${ }^{4}$, com os aportes da filosofia da linguagem

2 Prefácio da edição americana Toward a Philosopy of the Act (Austin:University Press, 1993)

3 Os estudos e pesquisas deste grupo foram iniciados em 2002, reunindo pesquisadores e alunos de iniciação científica da UFPE. Foram desenvolvidas pesquisas que resultaram em publicações individuais e conjuntas, em contato e troca com outras universidades: o Grupo e Pesquisa Linguagem, Identidade e Memória (PU-SP) e a APST - Analyse Pluridisciplinaire des Situations de Travail (Univ.de Provence, França). Na atualidade, o grupo desenvolve pesquisas e/ou orienta teses de mestrado e doutorado em torno da ideias contidas nas obras de Bakhtin e o Círculo e da análise dialógica de discursos em diferentes domínios: midiático, jurídico, literário, artístico, clínico, educacional, de saúde, ciência e tecnologia nas relações sociais e de trabalho.

4 O Grupo de Pesquisa Linguagem, Identidade e Memória, criado em 2000, no âmbito do Programa de Estudos Pós-Graduados em Linguística Aplicada e Estudos da Linguagem (LAEL - PUC-SP) e certificado no 
bakhtiniana e de outros filósofos ${ }^{5}$ com os quais dialogou direta ou indiretamente, remonta o período de 2007-10, com o desenvolvimento de projetos de pesquisa de intervenção e impacto social, como o Cidades Saudáveis ${ }^{6}:$ uma proposta humanista para a promoção da saúde de idosos ${ }^{7}$, no município de Sairé/Pernambuco' e Dor e Capacidade Funcional ${ }^{8}$ : a ação da memória, no acontecimento da velhice ${ }^{9}$, desenvolvidos com a participação de alunos de iniciação científica os quais resultaram em publicações de artigos e capítulo de livro, como A propósito da Filosofia do Ato: Bakhtin e a pesquisa Cientifica nas Ciências Humanas (2009) ${ }^{10}$, Vida e envelhecimento: uma re-leitura filosófica de Mikhail Bakhtin e Henri Bergson (2010) $)^{11}$.

Nesses estudos foi possível demonstrar como o ato/ação responsável, referido por Bakhtin, pode ser exemplificado através da ação operada pela memória ${ }^{12}$ dos idosos, desencadeada pela entrevista narrativa, convocando-os a agir, a criar um discurso a partir das perguntas provocadas, como um ato responsável e responsível de construir e disputar sentidos na unicidade do acontecimento do ser. Em nenhum momento o discurso narrativo está dissociado das próprias condições sociais do indivíduo ou é indicativo de uma verdade que é dada a priori sobre o real. Ao contrário, da posição única que o idoso ocupa no acontecimento da memória de sua vida, ele significa de maneira única e irrepetível, enunciando a partir de dois planos de determinação valorativa do mundo - de um eu para mim, enquanto ser humano, ocupando um lugar único na existência, e de um eu para o outro, ou outros (enquanto idoso). O idoso, quando perguntado, pelo pesquisador, se alguma coisa mudara do tempo que era jovem, ele reativa, do lugar único que ocupa na existência de sua vida, a memória do passado que se estende à memória do presente:

E como mudou! E mudô muito, [...] da água pro vinho. Porque, pra começo, há dez ou doze anos atrás, ou mais, uns quinze ano ou vinte atrás, três hora da manhã eu já tava no batente, como se diz, pronto pra trabalhar, pra cortar capim, criava uns bichinho... E quando é hoje

CNPq, em 2005, reúne pesquisadores e estudantes das seguintes universidades: Pontifícia Universidade Católica de São Paulo, Universidade de São Paulo, Universidade Estadual de Campinas, Universidade Federal de Pernambuco, Universidade Federal de Uberlândia, Universidade Federal da Bahia, Paris VIII (França). As pesquisas do grupo articulam-se em torno da análise dialógica do discurso (ADD), de natureza diversa (verbais, verbo-visuais, documentais, midiáticos, etc), os estudos da filosofia da linguagem e da educação, a história das ideias, os estudos de antologias hispano-americanas, os letramentos e ensino, a formação de professores em língua materna; e nas traduções de textos inéditos de Bakhtin e do Círculo para português.

5 Como é o caso do francês Henri Bergson, do lituano naturalizado francês, Emmanuel Lévinas, e do alemão Martin Heidegger.

6 Projeto desenvolvido em parceria com a UFPE, o Governo do Estado de Pernambuco e a Secretaria de Saúde do município de Sairé, PE.

7 No Brasil, a projeção das taxas de crescimento de idosos, na população, ficará em torno dos atuais $8,6 \%$ de idosos para 13\% em 2020, podendo chegar a 20\% da população em 2050 (IBGE, 1980;1991;2000). A cidade de Sairé, situada na região do Agreste pernambucano, destaca-se por possuir $10,5 \%$ de indivíduos $(1.857$ pessoas) com mais de 60 anos, índice acima da média nacional.

8 Projeto desenvolvido com pacientes idosos, em tratamento da dor, no Hospital de Clínicas da Universidade Federal de Pernambuco.

9 O objetivo do projeto foi identificar, descrever e interpretar o significado da dor, expressa nos acentos apreciativos contidos nos discursos dos idosos e seu impacto em suas capacidades funcionais.

10 Revista Bakhtiniana, n.1, 2009: pp.42-56. http://www.linguagemememoria.com (last accessed october, 2014).

11 In: Círculo de Bakhtin: diálogos (in)possíveis. Paula, L.de e Stafussa,G. (Orgs.)(Campinas: Mercado de Letras, 2010), pp. 101-22.

12 Na percepção de Bergson (2005: 18), o envelhecimento parece ser um processo vital no qual se inscreve o inexorável registro do tempo (duração), o que implica a existência de uma memória orgânica: 'o fundo estrito de nossa existência consciente é memória, isto é, o prolongamento do passado no presente, isto é, enfim, duração atuante e irreversível'. 
eu tô me levantano cinco e meia, seis hora a pulso, agarrado pelas parede. Saio, eu digo à mulher: "hoje eu num ando", mas vou [...] e volto, espaireço, tomo um pequeno, tal, tomo um remédio e assim continuo a luta... Só mudou de eu querer fazer e num poder. (AQS, 67 anos)

Como diria Bajtin (1997a: 48-9), é a unicidade do Ser, que possibilita que ele, o idoso, do seu lugar único no Ser, "veja e conheça um outro" (o jovem que habita nele pela memória), que "eu não o esqueça", que esse outro também exista para ele. Esta ação produtiva, que só pode ser produzida por ele, é que constitui o momento do dever, no qual assumimos a responsabilidade pela nossa unicidade. Isso não significa que o envelhecimento, enquanto unidade de significado do mundo da cognição (ciência) ou da cultura, não ocupe um momento do Ser e seja valorado diferentemente quando correlacionado com o eu (idoso) e com o outro (jovem), os quais estão impregnados de tons emocionalvolitivos completamente diferentes. "Isso não agride a unidade de semântica do mundo": ao contrário, "a eleva ao nível de unicidade própria do acontecer" (BAJTIN, 1997a: 79): "mudou de eu querer fazer" - como fazia no tempo que era jovem, e "não poder fazer" - no tempo presente como idoso. E o que mudou? Na literatura científica sobre o tema são relatadas múltiplas mudanças, como a perda progressiva da capacidade funcional, entendida como habilidades físicas e mentais necessárias e suficientes para a manutenção de uma vida independente e autônoma para o desempenho das atividades de vida diária (VIEIRA, 1996). A mudança constante da forma faz parte, portanto, de todo o ser vivo, como uma espécie de preparação de cada etapa do envelhecimento.

Em 2011 a pesquisadora obteve uma bolsa de pós-doutorado sênior do Conselho Nacional de Pesquisa Científica e Tecnológica (CNPq-Brasília) para desenvolver o projeto de pesquisa Ética e Pesquisa Científica nas Ciências Humanas: Diálogos Filosóficos com M.Bakhtin (2011-2012) ${ }^{13}$, sob a supervisão da profa. Dra. Beth Brait o qual resultou na publicação de Ética e Ciências Humanas: diálogos filosóficos entre M.Bakhtin e E.Lévinas (2012) ${ }^{14}$. Origens filosóficas da ética em Bakhtin: releituras da metafísica e da fenomenologia ontológico-hermenêutica $(2012)^{15}$.

Concluído o pós-doutorado e no retorno a sua universidade de origem, a pesquisadora iniciou novo projeto: Origens filosóficas da ética em Bakhtin: re-leituras da metafísica e da fenomenologia ontológico-hermenêutica (2012-2015), dos quais resultaram sub-projetos de iniciação científica, desenvolvidos por alunos orientandos da licenciatura em Letras: Filosofia ética da linguagem: a compreensão do Ser (2013-2014 - Pedro Henrique de Oliveira Simões); Filosofia ética da linguagem: coexistencialidade ontológica do homem (2013-2014 - Felipe Diego Batista); Filosofia ética da linguagem: o retorno ao autêntico/vida vivida e suas implicações para a compreensão do acontecimento do ser (2014-2015 - Pedro Henrique de Oliveira Simões); Caminhos do pensamento subjetivo para o tornar-se (inter)subjetivo: implicações para a compreensão do acontecimento do ser e do ato ético responsável (2015-2016 - Ricardo Lima Gomes); Ato ético, hermenêutica da facticidade e acontecimento do ser: uma análise dialógico-discursiva das manifestações de rua no Brasil em 2014-2015 (2015-2016 - Ana Elizabeth Oliveira da

13 Projeto desenvolvido no Programa de Estudos Pós-Graduados em Linguística Aplicada e Estudos da Linguagem da Pontifícia Universidade Católica de São Paulo, São Paulo-SP.

14 Ensaio publicado em Cadernos de Linguagem e Sociedade, vol. 13 (2), 2012, pp.185-206. http://seer.bee. unb.br/index.php/les (last accessed november, 2014).

15 Trabalho apresentado em 2011, na 14th International Bakhtin Conference, na Itália, e publicado em livro organizado por Zandwais, A., História das Ideias. Diálogos entre linguagem, cultura e história, pela (Passo Fundo: Editora da Universidade de Passo Fundo, 2012) pp. 192-215. 
Silva); dissertações e teses, projetos de mestrado e doutorado, desenvolvidos por alunos do Programa de Pós-Graduação em Letras, sob minha orientação: Relações de gênero: as formas de enunciação da identidade da mulher na mídia jornalística (Dissertação, 2008 - Marcelo Bernardo dos Santos); O discurso das trabalhadoras domésticas em formação (Dissertação, 2008 - Joseane Laurentino Brito da Cruz); Software: esboço de um estudo para as Ciências da Linguagem (Dissertação, 2010 - Aguinaldo Gomes de Souza); Análise dialógico-discursiva da atividade dos cuidadores de idosos em instituições geriátricas do Recife (Dissertação, 2010 - Ludmila Mota de Figueiredo Porto); A atividade de tutores a distância: uma análise bakhtiniana do prescrito e do vivido nos ambientes virtuais de aprendizagem (Tese, 2013 - Shirlei Marly Alves); Análise enunciativo-discursiva do guia prático dos cuidadores de idosos (Projeto de doutorado, 2014 - Ludmila Mota de Figueiredo Porto); A construção de conhecimento entre orientador e orientando na universidade: um processo de intervenção formativa (2014, Projeto de doutorado - Karla Daniele de Souza Araújo); O valor do trabalho doméstico não remunerado (2015, Projeto de doutorado - Joseane Lauretino de Brito); A ética em Bakhtin como limite interpretativo do direito: uma análise da decisão do Supremo Tribunal Federal no Habeas Corpus 82.424/RS (Projeto de mestrado - Bruna de Carvalho Chaves Peixoto) e ainda a escritura de estudos inéditos apresentados em congressos nacionais e internacionais, como $\mathrm{Di}$ mensão ontológico-hermenêutica no pensamento ético bakhtiniano e heideggeriano e construção do sentido ${ }^{16}$ (2013) e Bakhtin e Heidegger: a linguagem como experiência pensante (2014) ${ }^{17}$, Bakhtin e Heidegger: caminhos para a compreensão e interpretação do acontecimento do ser $(2014)^{18}$; Caminhos do pensamento subjetivo para o tornar-se (inter)subjetivo: uma abordagem filosófica da linguagem $(2016)^{19}$.

Abaixo transcrevemos os depoimentos de doutorandos acerca de suas experiências com a leitura de Por uma Filosofia do Ato Ético e seu impacto no desenvolvimento de seus projetos:

\section{O discurso das trabalhadoras domésticas em formação (Joseane Laurentino Brito da Cruz)}

Em seu estudo a pesquisadora analisou o discurso das trabalhadoras domésticas da cidade do Recife que passaram por um processo de qualificação organizado por um dos mais importantes sindicatos brasileiros - a Central Única dos Trabalhadores (CUT) -, cuja finalidade era promover a formação educacional e profissional visando conscientizar, a categoria, acerca do valor social dessa atividade, incentivando-as a lutarem por condições mais dignas de trabalho. Abaixo o depoimento da pesquisadora:

O objetivo de nossa pesquisa foi investigar como as trabalhadoras domésticas, submetidas a um processo de formação educativo-profissional, reagiam à palavra trazida pelo discurso de formação, ou seja, como se dava a construção identitária dessas trabalhadoras, enquanto

16 Trabalho apresentado na VIII Jornada do GP/CNPq Linguagem, identidade e Memória, por ocasião do 190. Intercâmbio Nacional de Pesquisas em Linguística Aplicada, São Paulo, outubro de 2013.

17 Trabalho apresentado, em 2014, no 13th International Conference on the History on the Languages Sciences, na Universidade de UTAD, Vila Real, Portugal.

18 Trabalho apresentado na IX Jornada do GP/CNPq Linguagem, identidade e Memória, UFPE, Recife, Pernambuco, em outubro de 2014 e publicado na Revista Baktiniana, vl. 10, n.3, 2015, pp. 186-204;225-242 http://revistas.pucsp.br.

19 Trabalho apresentado na X Jornada do GP/CNPq Linguagem, Entidade e Memória, por ocasião do $20^{\circ}$. Intercâmbio Nacional de Pesquisas em Linguística Aplicada, São Paulo, novembro de 2015 e aceito para publicação na Revista Desenredo, v. 12, nº 1, 2016. 
categoria, à luz dos novos conceitos introduzidos pelo projeto Trabalho Doméstico Cidadão. Para esse fim recorremos aos conceitos de ato e evento, no texto Para uma filosofia do ato, de Bakhtin, a fim de verificar como as trabalhadoras domésticas compreendiam, ressignificavam e reavaliavam essa palavra durante e após o processo, uma vez que esse acontecimento social e histórico ainda iria gerar uma série de atos ininterruptos e contínuos que se projetavam num devir, sinalizando para a transformação da visão dessas trabalhadoras através do excedente de visão, a partir do qual elas viam o outro e, aos poucos, iam se apropriando de suas palavras, ora concordando, ora discordando do que fora dito, nesse diálogo inconcluso e ininterrupto entre as trabalhadoras e todo esse universo vivo de palavras que se encontram nos discursos que circulam nas estruturas sociais nas quais estavam inseridas.

\section{A atividade de tutores a distância: uma análise bakhtiniana do prescrito e do vivido nos ambientes virtuais de aprendizagem (Shirlei Marly Alves)}

$\mathrm{Na}$ tese de doutorado a pesquisadora tinha, como objetivo, compreender as singularidades da atividade de tutoria, no ensino a distância (Ead) e suas constantes ressingularizações na dinâmica das relações discursivas entre o tutor e os 'outros' (instituição, professores e alunos). Para Alves,

(...) a concepção de linguagem a conduzir o trabalho do analista do trabalho só poderá ser aquela cuja primazia esteja na relação entre sujeitos, cuja construção se dá na dinâmica ininterrupta dos discursos situados, os quais engendram formas de vida, na arena dialógica em que os seres humanos se encontram.[...] É perceptível a convergência entre essa concepção de ato, em Bakhtin, e a de atividade, conforme a episteme ergológica, visto que, em ambas, o agir humano ocorre em acontecimentos únicos, com as singularidades que lhe são inerentes. Logo, só podem ser apreendidos no contato do pesquisador com os sujeitos em seu existir-acontecimento, a exemplo dos trabalhadores, considerados não como objetos de observação, mas, sobremaneira, como seres singulares, que, no seu cotidiano de trabalho, mobilizam competências construídas e reconstruídas a partir de sua história, emoções, memórias e outros elementos de natureza subjetiva.

\section{Análise enunciativo-discursiva do guia prático dos cuidadores de idosos (Ludmila Mota de Figueiredo Porto)}

Em seu projeto de tese de doutorado, Porto deu continuidade aos estudos sobre a atividade dos cuidadores de idosos em instituições geriátricas da cidade do Recife ${ }^{20}$, dessa feita voltando-se à análise dialógica dos discursos contidos em três manuais técnicos para cuidadores, reconhecidos pelo Ministério da Saúde brasileiro. Em seu estudo, preconiza que se aplique o 'ato ético do cuidado para com o ser-humano-idoso', asseverando 'que o cuidado ético' deva estar sempre subjacente a 'todos os outros modelos de cuidado', na medida em que 'o ser-cuidadoso' é, sobretudo, um dever ético o qual serve de 'guia para as relações cuidadosas dos seres humanos entre si'. Abaixo o depoimento da pesquisadora:

Por ocasião do Doutorado, cursei a disciplina de Filosofia da Linguagem com a Profa. Dra. Maria Cristina Hennes Sampaio, orientadora de minha tese, a qual ampliou a discussão em torno da obra de Bakhtin, tomando por base Para uma filosofia do ato, obra que considero essencial para a compreensão daquilo que Bakhtin denomina de Filosofia Primeira, cujo

20 Participaram do estudo três Instituições de Longa Permanência da cidade do Recife as quais abrigavam em torno de 30 idosos que recebem cuidados diários de enfermeiros e cuidadores. 
objeto de estudo é o ato ético, em sua eventicidade, o qual é abordado na confluência entre o conteúdo-sentido e a realidade histórica do seu acontecimento, no qual adquire um matiz axiológico. A leitura da obra é essencial para a compreensão da visão bakhtiniana de linguagem, sendo o ato concreto também um ato de linguagem, um agir responsiva e responsavelmente com o outro. As relações dialógicas estabelecidas com outros textos de Bakhtin e com outros filósofos, a exemplo de Heidegger e Kant, foram de extrema importância para minha formação nos estudos bakhtinianos, bem como para a produção de minha tese, que discute o ato concreto e o acontecimento do ser como elementos-chave para a compreensão do ser-cuidadoso. Na minha visão, Para uma Filosofia do Ato é a obra que inicia e, ao mesmo tempo, permite o acabamento, ainda que transitório, do sentido, em Bakhtin.

\section{A construção de conhecimento entre orientador e orientando na universidade: um proces- so de intervenção formativa (Karla Daniele de Souza Araújo)}

Em seu projeto de doutorado, Araújo analisa como se constrói o conhecimento entre orientando e orientador em um Programa de Pós-Graduação em Letras de uma universidade pública brasileira. A pesquisadora entende a orientação acadêmica como um espaço formativo no qual sujeitos, sócio-historicamente situados, apresentam suas necessidades e, em busca de soluções, estabelecem uma relação discursiva dialógica, confrontando e avaliando pontos de vista, reconstruindo sentidos e compartilhando significados. Nesse sentido, o sujeito histórico seria aquele que experencia o mundo desde seu lugar único e singular, assumindo seus pensamentos e ações como atos éticos responsáveis dos quais não pode se esquivar. Vejamos seu depoimento abaixo:

(...) o homem não vai ao mundo para investigar o objeto, ele é no mundo, e de dentro dessa abertura está lançado junto com as coisas, de onde pode chegar a conhecê-las, vivenciando-as. A verdade, como abertura, responde então à verdade do ser, ao ser como acontecimento, que vem a ser a verdade ontológica (em comparação com a verdade ôntica, do ente). A ideia de abertura desestabiliza o fazer científico, pois põe em cheque seus métodos e objetivos. Quer dizer, se não podemos mais contar com o encontro da verdade como momento culminante da pesquisa, para onde ela apontará? (...) Sendo impossível negar a multiplicidade de olhares, e entendendo que não existe a priori uma verdade absoluta, é preciso reconhecer a dúvida como valor que é a base da nossa vida enquanto proceder ativo, e isso de modo algum entra em contradição com a cognição teórica, apenas assume o modo de ser do homem enquanto projeto, possibilidade, potência.

\section{Experiência de ensino: introdução da disciplina Filosofia da Linguagem}

A experiência com a introdução da disciplina Filosofia da Linguagem, com o aporte das ideias filosóficas de Bakhtin, deu-se, de forma ainda experimental, nos idos dos anos 2007 e 2010, com a matrícula de um pequeno mas interessado grupo de alunos, sendo nosso objetivo oferecer uma visão ampla dos fundamentos filosóficos das principais teses de Bakhtin e o Círculo, considerando seus princípios epistemológicos e metodológicos bem como suas implicações e aplicações para a pesquisa em Ciências Humanas. O resultado desse trabalho é descrito abaixo: 


\section{Gráfico 121}

\begin{tabular}{|c|c|c|}
\hline Autor e Ano & Título do trabalho & Objetivo \\
\hline $\begin{array}{l}\text { Adelmo Galindo } \\
\text { (Mestrando - 2007) }\end{array}$ & $\begin{array}{l}\text { Reflexões ancoradas em } \\
\text { Bakhtin: o sujeito e a } \\
\text { linguagem. }\end{array}$ & $\begin{array}{l}\text { Abordar - a partir de duas obras bakhtinianas } \\
\text { (Para uma filosofia do ato ético e Marxismo } \\
\text { e filosofia da linguagem) -, as concepções de } \\
\text { sujeito e de linguagem, enfatizando especialmente } \\
\text { a interação humana mediante a língua em uso } \\
\text { (seja ela falada ou escrita). }\end{array}$ \\
\hline $\begin{array}{l}\text { André Alexandre Padilha } \\
\text { Leitão (Doutorando - } \\
\text { 2007) }\end{array}$ & $\begin{array}{l}\text { A arquitetônica da } \\
\text { responsibilidade na } \\
\text { Web } 2.0 \text { e a questão da } \\
\text { autoria. }\end{array}$ & $\begin{array}{l}\text { Investigar a construção do sujeito responsivo } \\
\text { na web } 2.0 \text { como autor do conteúdo produzido } \\
\text { nos sites de conteúdo aberto e colaborativo, } \\
\text { principalmente em sites wiki, tomando por base } \\
\text { as categorias de ato/atividade, evento, ética e } \\
\text { responsibilidade de Mikhail M. Bakhtin. }\end{array}$ \\
\hline $\begin{array}{l}\text { Carolina Leal Pires } \\
\text { (Mestranda - 2007) }\end{array}$ & $\begin{array}{l}\text { Onde está Bakhtin? } \\
\text { Buscando identificar } \\
\text { contribuições } \\
\text { do pensamento } \\
\text { bakhtiniano à Análise } \\
\text { Semiolinguística do } \\
\text { Discurso. }\end{array}$ & $\begin{array}{l}\text { Identificar as contribuições do pensamento } \\
\text { bakhtiniano à Análise Semiolinguística do } \\
\text { Discurso de Patrick Charaudeau. }\end{array}$ \\
\hline $\begin{array}{l}\text { Gerenice Ribeiro de } \\
\text { Oliveira Cortes (Mestranda } \\
\text { - 2007) }\end{array}$ & $\begin{array}{l}\text { Dilogismo e Alteridade } \\
\text { no Discurso Científico. }\end{array}$ & $\begin{array}{l}\text { Analisar em que medida o dialogismo e a } \\
\text { alteridade figuram e se configuram o/no discurso } \\
\text { científico, por ser este, na tradição racionalista, } \\
\text { concebido como 'neutro' e objetivo. }\end{array}$ \\
\hline $\begin{array}{l}\text { Josemar José Barbosa } \\
\text { (Doutorando - 2007) }\end{array}$ & $\begin{array}{l}\text { Alteridade e Dialogismo: } \\
\text { a eterna busca do Outro. }\end{array}$ & $\begin{array}{l}\text { O estudo pretende discutir as seguintes questões: } \\
\text { o que fazer quando o desejo por comunicar-se é } \\
\text { sobreposto pela frustrante inabilidade de desvelar- } \\
\text { se diante do outro? Que mecanismos se utilizam } \\
\text { os sujeitos na sua busca constante por descobrir- } \\
\text { se? É possível construir-se sem que isto implique, } \\
\text { primeiro, a construção do outro? }\end{array}$ \\
\hline $\begin{array}{l}\text { Maria Aldenora Cabral de } \\
\text { Araújo (Mestranda - 2007) }\end{array}$ & $\begin{array}{l}\text { O papel dialógico da } \\
\text { memória discursiva nas } \\
\text { produções escritas em } \\
\text { Língua Inglesa como } \\
\text { idioma estrangeiro. }\end{array}$ & $\begin{array}{l}\text { Compreender qual o papel da memória discursiva } \\
\text { em um projeto de fala entre Língua Materna e } \\
\text { Língua Inglesa. }\end{array}$ \\
\hline Autor e Ano & Título trabalho & Objetivo \\
\hline $\begin{array}{l}\text { Ludmila Mota de } \\
\text { Figueiredo Porto } \\
\text { (Doutoranda }-2010)\end{array}$ & $\begin{array}{l}\text { Pêcheux e Bakhtin } \\
\text { em suas raízes: } \\
\text { aproximações. }\end{array}$ & $\begin{array}{l}\text { Resgatar alguns conceitos nas obras de Pêcheux } \\
\text { e Bakhtin, estabelecendo aproximações entre as } \\
\text { identidades teóricas de suas propostas. }\end{array}$ \\
\hline $\begin{array}{l}\text { Rita de Kássia Kramer } \\
\text { Wanderley (Mestranda - } \\
\text { 2010). }\end{array}$ & $\begin{array}{l}\text { Ato e responsabilidade } \\
\text { na filosofia moral de } \\
\text { Para uma filosofia do } \\
\text { ato responsável. }\end{array}$ & $\begin{array}{l}\text { Refletir acerca de alguns conceitos talhados } \\
\text { pelo autor e debatidos durante nosso trabalho na } \\
\text { disciplina. }\end{array}$ \\
\hline $\begin{array}{l}\text { Shirlei Marly Alves } \\
\text { (Doutoranda - 2010) }\end{array}$ & $\begin{array}{l}\text { 'Instinto': antípodas } \\
\text { da investigação em } \\
\text { Ciências Humanas. }\end{array}$ & $\begin{array}{l}\text { Verificar como o conceito de ato ético } \\
\text { responsável, de Bakhtin, se associa à ação dos } \\
\text { dois personagens (o antropólogo Ethan Powel } \\
\text { e o psiquiatra Theo Caulder), na obra fílmica } \\
\text { 'Instinct' (dirigido por Jon Turteltaub, 1999), } \\
\text { de modo a contribuir para uma discussão sobre } \\
\text { a atitude do pesquisador diante do outro - o } \\
\text { pesquisado -, no âmbito das Ciências Humanas. }\end{array}$ \\
\hline
\end{tabular}

21 Trabalhos de conclusão de Curso, apresentados pelos alunos entre 2007-10, na Disciplina Filosofia da Linguagem. 
No primeiro semestre de 2011 afastei-me da UFPE para fazer um pós-doutorado na Pontifícia Universidade Católica de São Paulo, no Programa de Estudos Pós-Graduados em Linguística Aplicada e Estudos da Linguagem, sob a supervisão da professora Beth Brait, com o projeto Ética e Pesquisa Científica nas Ciências Humanas: Diálogos Filosóficos com M. Bakhtin ${ }^{22}$. No segundo semestre de 2012 retornei às minhas atividades acadêmicas na UFPE e, em 2013 e 2015, voltei a oferecer a disciplina Filosofia da Linguagem, agora com o objetivo e programa reformulados, passando a considerar, nos fundamentos ético-filosóficos das principais teses de Bakhtin e o Círculo, em torno da Filosofia da Linguagem, os aportes da Fenomenologia, da Metafísica, da Ontologia e da Hermenêutica ${ }^{23}$ que os norteiam e suas implicações e aplicações na pesquisa em Ciências Humanas. Os gráficos, abaixo, ilustram os trabalhos apresentados pelos alunos ao final do semestre:

\section{Gráfico $2^{24}$}

\begin{tabular}{|l|l|l|}
\hline Autor e Ano & Título do trabalho & Objetivo \\
\hline Adiniz Mendes (Doutorando - 2013) & $\begin{array}{l}\text { Alguns conceitos } \\
\text { bakhtinianos sobre as } \\
\text { Ciências Humanas }\end{array}$ & $\begin{array}{l}\text { Refletir e sintetizar a visão de Bakhtin } \\
\text { sobre as Ciências Humanas, tomando } \\
\text { como base o texto O problema do texto } \\
\text { na Linguística, na Filologia e em outras } \\
\text { ciências humanas: uma experiência } \\
\text { de análise filosófica; Metodologia das } \\
\text { Ciências Humanas e Apontamentos de } \\
\text { 1970 a 1971. }\end{array}$ \\
\hline Carla Richter (Mestranda - 2013) & $\begin{array}{l}\text { Nas teias da } \\
\text { singularidade: diálogos } \\
\text { entre Bakhtin, a } \\
\text { Linguística Aplicada e } \\
\text { a Teoria da Atividade } \\
\text { Sócio-Histórico-Cultural }\end{array}$ & $\begin{array}{l}\text { Colocar em diálogo o pensamento } \\
\text { filosófico de Bakhtin, a Linguística } \\
\text { Aplicada e a Teoria da Atividade Sócio- } \\
\text { Histórico-Cultural. }\end{array}$ \\
\hline $\begin{array}{l}\text { Erasmo da Silva Ferreira (Mestrando } \\
\text { - 2013) }\end{array}$ & $\begin{array}{l}\text { Bakhtin e Heidegger: } \\
\text { uma contribuição à } \\
\text { Filosofia da Língua(gem) }\end{array}$ & $\begin{array}{l}\text { Refletir acerca da natureza filosófica da } \\
\text { linguagem, nas visões de Bakhtin (Para } \\
\text { uma filosofia do ato) e Heidegger (Ser e } \\
\text { Tempo). }\end{array}$ \\
\hline
\end{tabular}

22 Nesse estudo optou-se por retomar temas que se destacam na obra filosófica de Bakhtin Hacia una Filosofia del Acto Ético. De los borradores e otros escritos (Barcelona: Anthropos, 1977) - tais como relações ser-ente, homem-existência, ser-alteridade-responsabilidade e que foram revisitados no confronto dialógico das obras: El ser y el tempo, do filósofo alemão Martin Heidegger (El Salvador/Buenos Aires: Fondo de Cultura Económica, 2010), e Entre nós: ensaios sobre a alteridade, do lituano, naturalizado francês, Emmanuel Lévinas (Stefano Pivatto Petrópolis: Editora Vozes, 2009).

23 Como já observara Caryl Emerson, na obra Os 100 primeiros anos de Mikhail Bakhtin (Trad. Pedro Jorgensen Jr., Rio de Janeiro: Difel, 2003, 19), 'não está claro o lugar de onde veio a tradição filosófica que o nutriu e ainda está por ser esclarecida', já que no corpo da obra, propriamente dita, existem referências esparsas, de Bakhtin, a outros filósofos, como é o caso dos alemães Immanuel Kant, Heinrich Rickert (neokantiano), Hermann Cohen, Friedrich Nietzche, Arthur Shopenhauer ou o francês Henri Bergson e o inglês Thomas Hobbes. As demais são de responsabilidade dos tradutores e aparecem em notas de rodapé, ou são alusões em prefácios e posfácios das edições traduzidas na Europa, Estados Unidos e América do Sul. Como relatado por Faracco, no posfácio à edição brasileira da obra Para uma filosofía do ato responsável (Trad. de Valdemir Miotello e Carlos Alberto Faracco. São Carlos: Pedroejoaoeditores, 2010, p. 149), é conhecida a pouca importância atribuída, por Bakhtin, a citações e referências, sendo-lhe atribuído o enunciado de que "elas eram desnecessárias para o leitor competente e inúteis para o não qualificado". Quer concordemos ou não, com Bakhtin, o fato é que o jovem filósofo, com sólida formação em estudos clássicos, que lia fluentemente o alemão, transitou por várias tradições, como a filosofia grega, a fenomenologia, a hermenêutica, a ontologia e a metafísica - conforme atestam seus escritos datados de 1920 .

24 Trabalhos de Conclusão de Curso em 2013, na Disciplina Filosofia da Linguagem. 


\begin{tabular}{|c|c|c|}
\hline $\begin{array}{l}\text { Felipe Augusto Santana do Nascimento } \\
(\text { Mestrando - 2013) }\end{array}$ & $\begin{array}{l}\text { Dois ou três pontos } \\
\text { sobre a singularidade } \\
\text { e a responsabilidade } \\
\text { na pesquisa científica } \\
\text { em ciências humanas: } \\
\text { considerações a partir } \\
\text { de } \text { Para uma filosofia do } \\
\text { ato, de M. Bakhtin. }\end{array}$ & $\begin{array}{l}\text { Discutir, a partir da obra Para uma } \\
\text { filosofia do ato, de M. Bakhtin, as } \\
\text { implicações das noções de singularidade } \\
\text { e responsabilidade para a pesquisa } \\
\text { científica nas Ciências Humanas - } \\
\text { mais especificamente nos estudos da } \\
\text { linguagem. }\end{array}$ \\
\hline $\begin{array}{l}\text { Karla Daniele de Souza Araújo } \\
\text { (Doutoranda - 2013) }\end{array}$ & $\begin{array}{l}\text { Sobre a Ciência e o } \\
\text { Homem: um ensaio sobre } \\
\text { o conhecimento ético. }\end{array}$ & $\begin{array}{l}\text { Refletir sobre a construção do } \\
\text { conhecimento entre orientandos de } \\
\text { mestrado e seus orientadores, na atividade } \\
\text { social de orientação acadêmica, com o } \\
\text { foco sobre a dinâmica de (re)produção de } \\
\text { saberes. }\end{array}$ \\
\hline $\begin{array}{l}\text { Romana Maria Moreira } \\
(\text { Mestre em filosofia - 2013) }\end{array}$ & $\begin{array}{l}\text { Aportes hermenêticos } \\
\text { no discurso da filosofia } \\
\text { do ato ético de Bakhtin. }\end{array}$ & $\begin{array}{l}\text { Identificar e aplicar fundamentos } \\
\text { hermenêuticos, no discurso da obra Para } \\
\text { uma Filosofia do Ato, de Bakhtin, com } \\
\text { uma metodologia centrada na utilização } \\
\text { dos fundamentos da hermenêutica } \\
\text { filosófica. }\end{array}$ \\
\hline $\begin{array}{l}\text { Thais de Andrade Lima (Mestre - } \\
\text { 2013) }\end{array}$ & $\begin{array}{l}\text { O pensamento } \\
\text { participativo em Bakhtin: } \\
\text { passos trilhados em Para } \\
\text { uma filosofia do ato. }\end{array}$ & $\begin{array}{l}\text { Pensar,participativamente, construtos } \\
\text { teóricos desenvolvidos de maneira } \\
\text { interligada, tais como o ato ético e a } \\
\text { arquitetônica do ser, e refletir sobre } \\
\text { os resultados metodológicos de um } \\
\text { pensamento decorrente da singularidade } \\
\text { do ato ético para os estudos da linguagem. }\end{array}$ \\
\hline
\end{tabular}

\section{Gráfico $3^{125}$}

\begin{tabular}{|c|c|c|}
\hline Autor e Ano & Título do trabalho & Objetivo \\
\hline Arcélio Alves Fortes (Mestre - 2015) & $\begin{array}{l}\text { Ser e idade: análise } \\
\text { introdutória da mudança } \\
\text { de limite de idade para } \\
\text { adolescentes e pessoa } \\
\text { idosa sob a ótica da } \\
\text { arquitetônica de Bakhtin. }\end{array}$ & $\begin{array}{l}\text { Contribuir, mediante a análise de } \\
\text { percepções individuais, no contexto das } \\
\text { diversidades de regiões brasileiras e da } \\
\text { qualidade de vida ofertada à população, } \\
\text { com as discussões vigentes no tocante } \\
\text { a modificação de limite de idade para } \\
\text { maioridade penal e aposentadoria, sob a } \\
\text { abordagem do ser, exposta por Bakhtin, em } \\
\text { Por uma Filosofia do Ato Ético. }\end{array}$ \\
\hline $\begin{array}{l}\text { Bruna de Carvalho Chaves Peixoto } \\
\text { (Mestranda 2015) }\end{array}$ & $\begin{array}{l}\text { O dinamismo } \\
\text { interpretativo do discurso } \\
\text { jurídico do STF na } \\
\text { decisão sobre o racismo: } \\
\text { uma análise dialógica do } \\
\text { ato responsável. }\end{array}$ & $\begin{array}{l}\text { Analisar, tomando como base teórica o } \\
\text { dialogismo bakhtiniano, a concepção de } \\
\text { responsividade e ética, o papel do contexto } \\
\text { sócio histórico ideológico nas decisões } \\
\text { do STF acerca de questões polêmicas, } \\
\text { especificamente o Acórdão, através do } \\
\text { qual se decidiu que o discurso de ódio } \\
\text { contra judeus era considerado crime de } \\
\text { racismo e seria imprescritível, assim como } \\
\text { previsto na Constituição. }\end{array}$ \\
\hline
\end{tabular}

25 Trabalhos de Conclusão de Curso em 2015, na Disciplina Filosofia da Linguagem. 


\begin{tabular}{|c|c|c|}
\hline $\begin{array}{l}\text { Ceuline Maria Medeiros Santiago } \\
\text { (Graduanda-2015) }\end{array}$ & $\begin{array}{l}\text { Ética e Gênero Social: } \\
\text { uma leitura de Hacia } \\
\text { una Filosofia del Acto } \\
\text { Ético. }\end{array}$ & $\begin{array}{l}\text { O presente estudo tem por objetivo refletir } \\
\text { sobre o ser no contexto real e concreto } \\
\text { da vida de fato vivida, considerando as } \\
\text { determinações teóricas que pretendem } \\
\text { conceber um único modo de ser mulher e } \\
\text { homem. Em que lugar estaria, no âmbito } \\
\text { dessas determinações, a irrefutável } \\
\text { singularidade do ser? Como conceber } \\
\text { tal singularidade no cerne das relações } \\
\text { fincadas entre os seres no mundo? Haveria } \\
\text { um sentido ético no ser mulher e ser } \\
\text { homem? }\end{array}$ \\
\hline \begin{tabular}{|l} 
Iago de Araújo Pereira \\
(Mestrando-2015)
\end{tabular} & \begin{tabular}{|l} 
O papel do Coordenador \\
Pedagógico em r um \\
curso de Línguas para \\
Mobilidade Estudantil \\
uma reflexão.
\end{tabular} & $\begin{array}{l}\text { O presente estudo tem por objetivo } \\
\text { compreender como o coordenador } \\
\text { pedagógico (CP) contribui para que } \\
\text { ocorra a produção de conhecimentos } \\
\text { compartilhados durante as interações } \\
\text { com os professores que compõe o corpo } \\
\text { docente do curso. }\end{array}$ \\
\hline $\begin{array}{l}\text { Joseane Laurentino Brito (Doutoranda } \\
-2015 \text { ) }\end{array}$ & $\begin{array}{l}\mathrm{O} \text { ato ético e e o } \\
\text { acontecimento do ser em } \\
\text { Bakhtin. }\end{array}$ & $\begin{array}{l}\text { O estudo tem por objetivo discutir } \\
\text { os conceitos de "ato" e "ser-evento", } \\
\text { presentes na obra de Bakhtin (1997), Para } \\
\text { uma filosofia do ato, relacionando-os ao } \\
\text { discurso das mulheres que realizam o } \\
\text { trabalho doméstico não-remunerado. }\end{array}$ \\
\hline $\begin{array}{l}\text { Luiz Carlos Carvalho de Castro } \\
\text { (Mestre-2015) }\end{array}$ & $\begin{array}{l}\text { O acontecimento do ser: } \\
\text { um estudo dialógico do } \\
\text { pensamento filosófico de } \\
\text { Heidegger e Bakhtin. }\end{array}$ & $\begin{array}{l}\text { O estudo tem por objetivo compreender a } \\
\text { constituição do ser a partir do pensamento } \\
\text { filosófico de M. Bakhtin e M.Heidegger. }\end{array}$ \\
\hline $\begin{array}{l}\text { Paulo Eduardo Aranha de Sá Barreto } \\
\text { Batista (Doutorando - 2015) }\end{array}$ & $\begin{array}{l}\text { O ato de representar } \\
\text { discurso parlamentar. }\end{array}$ & $\begin{array}{l}\text { Ao relatar a fala de outrem, o relator do } \\
\text { discurso parlamentar tem dois caminhos } \\
\text { básicos: manter as mesmas palavras } \\
\text { ou parafraseá-las. Em nosso projeto de } \\
\text { pesquisa de doutorado, pretendemos } \\
\text { observar o comportamento desse } \\
\text { fenômeno em uma situação específica: } \\
\text { a redação das atas das sessões plenárias } \\
\text { do Poder Legislativo de João Pessoa - } \\
\text { Pb. Nesse caso, o sujeito redator está } \\
\text { simultaneamente livrel da exigência da } \\
\text { transcrição, mas preso ao fato de que } \\
\text { o conteúdo impresso será apreciado } \\
\text { pelos múltiplos sujeitos falantes, os } \\
\text { parlamentares, para ser aprovado ou não } \\
\text { como registro histórico para os anais da } \\
\text { câmara. }\end{array}$ \\
\hline Solange Carvalho (Doutoranda - 2015) & $\begin{array}{l}\text { O acontecimento do ser } \\
\text { Xucuru. }\end{array}$ & $\begin{array}{l}\text { O objetivo deste ensaio é descrever o } \\
\text { acontecimento do ser xucuru - grupo } \\
\text { indígena localizado em Pesqueira-PE, que } \\
\text { vivencia um processo de resgate de sua } \\
\text { língua ancestral perdida }- \text {, pelo viés da } \\
\text { arquitetônica do mundo de Bakhtin. }\end{array}$ \\
\hline
\end{tabular}




\section{Considerações finais}

As descrições dos temas privilegiados tanto nos trabalhos de conclusão de disciplina, como nos estudos desenvolvidos por alunos de iniciação científica, em torno das ideias filosóficas bakhtinianas, quanto nos projetos de pesquisa de alunos pós-graduandos e nas pesquisas empíricas, desenvolvidas por nós no âmbito do Programa de PósGraduação em Letras da UFPE, parecem sinalizar que o projeto filosófico de Bakhtin, em relação à experiência com a linguagem, indica um caminho diferente daquele proposto pelas ciências, particularmente a linguística, a metafísica e a psicologia, o qual só pode concretizar-se na experiência vivida.

Voltando à reivindicação de Bakhtin de instaurar uma filosofia primeira, que não concebesse o ser metafisicamente, como objeto, contraposto ao sujeito, pressupõe aceitar que o ser é um evento que só pode acontecer na linguagem. Nesse sentido, o pensamento não será mais apenas um ir às próprias coisas, utilizando-se de uma linguagem-instrumento, pois, se é a linguagem que proporciona a abertura para o mundo e confere ser aos entes, o caminho que devemos trilhar, para chegar ao ente, é a palavra.

Além disso, há de se considerar que a compreensão (sentido) do ato responsável no acontecimento do ser-no-mundo, passa necessariamente por um outro tipo de compreensão que não se reduz e nem se confunde com uma mera explicação que se possa encontrar em algum sistema fundante universal regido pela razão, a exemplo dos métodos racionais (de fundar e explicar) da ciência. Assim sendo, para fazer uma experiência pensante, com a linguagem, não se pode permanecer numa pré-compreensão de um mundo já dado, conhecido, explicado, de um sentido estabilizado. A compreensão que se pretende é aquela que só pode ser encontrada no dever-ser do ato responsavelmente vivido, ou seja, trata-se daquilo que a própria vida dá a entender. Tal perspectiva abre um novo caminho para se pensar as formas de conhecimento da vida humana via linguagem.

\section{Referências}

BAJTIN, Mijail M. Hacia una filosofia del acto ético. De los boradores y otros escritos. Trad.Tatiana Bubnova. Rubi (Barcelona): Anthropos, 1997a.

BAKHTIN, M. Estética da Criação Verbal. Trad. Maria Ermantina G.G.Pereira. São Paulo: Martins Fontes, 1997b.

BERGSON, Henri. A evolução criadora. São Paulo: Martins Fontes, 2005.

SAMPAIO,M.C.H, ARAÚJO, K. D.de S., MACEDO, E.B.I. de. Bakhtin e Heidegger: caminhos para a compreensão e interpretação do acontecimento do ser, Bakhtiniana, vl. 10, n.3, 2015, pp. 186-204;225-242 http://revistas.pucsp.br/ .

SAMPAIO,M.C.H, Reflexões ético-filosóficas e bioéticas acerca do envelhecimento na perspectiva do desenvolvimento sustentável. Livro GED, Luciane de Paula (Org.), São Carlos: Pedro e João, 2014, pp.351-374.

SAMPAIO, M.C.H. Origens filosóficas da Ética em Bakhtin: re-leituras da Metafísica e da Fenomenologia ontológico-hermenêutica. Zandwais (Org.) História das Ideias. Diálogo entre linguagem, cultura e história. Porto Alegre: Editora UFRGS. Passo Fundo: Editora UPF, 2012, pp. 192-215.

SAMPAIO, M.Cristina Hennes. Ética e Ciências Humanas: diálogos filosóficos entre M.Bakhtin e E.Lévinas, Cadernos de Linguagem e Sociedade, vol.13(12), 2012, pp. 185-206.

VIEIRA, E.B. Manual de Gerontologia. Um Guia teórico-prático para profissionais, cuidadores e familiares. Rio de Janeiro: Revinter, 1996. 